\title{
Natural attenuation of heavy metals via secondary hydrozincite precipitation in an abandoned $\mathrm{Pb}-\mathrm{Zn}$ mine
}

MAX G GIANNETTA, ROBERT BENAIGES, JORDI CAMA, IGNASI M QUERALT AND JOSEP M SOLER

Institute of Environmental Assessment and Water Research (IDAEA-CSIC)

Presenting Author: giannetta1@gmail.com

The Victoria Mine in the Aran Valley (Spain) was active until 1950. The underground mine targeted sphalerite $(\mathrm{ZnS})$. Today, the relict tunnels and shafts are exposed to air and flowing water from infiltration, provoking oxidative dissolution, microbial activity, and precipitation of hydrozincite $[\mathrm{Zn} 5(\mathrm{CO} 3) 2(\mathrm{OH}) 6]$. Field sampling of the waters within the mine show somewhat elevated levels of $\mathrm{Cd}^{2+}(28 \mathrm{ppb})$ and $\mathrm{Zn}^{2+}(20 \mathrm{ppm})$. The source of the dissolved metals is likely from residual sphalerite, which is rich in $\mathrm{Cd}$ (upwards of 5,000 ppm). Preliminary geochemical modeling suggests that the measured $\mathrm{Cd}^{2+}$ and $\mathrm{Zn}^{2+}$ concentrations are lower than expected when compared to a system where sphalerite and the host rock are dissolving with excess oxygen. Therefore, some natural process(es) is likely acting as a sink for the metals.

Total digestions of hydrozincite samples from inside the mine reveal substantially elevated levels of heavy metals. Cadmium is frequently over 3,500 times more concentrated in the solid (107 $\mathrm{ppm})$ than in the adjacent water (28 ppb), and zinc displays a similar trend. Several metals such as $\mathrm{Mg}, \mathrm{As}, \mathrm{Pb}$, and $\mathrm{Ni}$ are also in abundance.

Hydrozincite can act as sink for metals via bio-induced coprecipitation with sunlight and photosynthetic microorganisms [1] - two components that do not exist in the mine. Nonetheless, DNA samples from the Victoria Mine were sequenced to look for potential culprits for biomineralization. We verified the presence of Firmicutes bacillus sp., which is associated with calcite biomineralization in analogous environments [2].

Geochemical speciation results confirm that although hydrozincite is oversaturated at many sampling locations, there exist several locations that display evidence of precipitation and concurrent undersaturation (e.g. SI $=-0.6$ ). This observation suggests that some form of biomineralization may be occurring as microbial activity has been confirmed.

The rate of precipitation of hydrozincite, coupled to the transport of reactants, requires further quantification through column experiments and reactive transport modeling in order to make reasonable predictions towards the extent of metal attenuation over time in the Victoria Mine.

[1] Podda et al. (2000). Applied and Environmental Microbiology, 66(11), 5092-5098.

[2] De Leo et al. (2012). International Journal of Speleology, 41(2), 125-136. 